\title{
Description of the microbiota in epidermal mucus and skin of sharks (Ginglymostoma cirratum and Negaprion brevirostris) and one stingray (Hypanus americanus)
}

\author{
Susana Caballero ${ }^{\text {Corresp., Equal first author, } 1 \text {, Ana Maria Galeano }}{ }^{\text {Equal first author, } 1}{ }^{\text {, Juan Diego Lozano }}{ }^{1}$, Martha Vives ${ }^{2}$ \\ ${ }^{1}$ Laboratorio de Ecología Molecular de Vertebrados Acuáticos, LEMVA, Biological Sciences Department, Universidad de los Andes, Bogota, Colombia \\ 2 Centro de Investigaciones Microbiológicas, CIMIC, Biological Sciences Department, Universidad de los Andes, Bogota, Colombia \\ Corresponding Author: Susana Caballero \\ Email address: sj.caballero26@uniandes.edu.co
}

Skin mucus in fish is the first barrier between the organism and the environment but the role of skin mucus in protecting fish against pathogens is not well understood. During copulation in sharks, the male bites the female generating wounds, which are then highly likely to become infected by opportunistic bacteria from the water or from the male shark's mouth. Describing the microbial component of epithelial mucus may allow future understanding of this first line of defense in sharks. In this study, we analyzed mucus and skin samples obtained from 19 individuals of two shark species and a stingray: the nurse shark (Ginglymostoma cirratum), the lemon shark (Negaprion brevirostris) and the southern stingray (Hypanus americanus). Total DNA was extracted from all samples, and the bacterial 16S rRNA gene (region V3-V4) was amplified and sequenced on the Ion Torrent Platform. Bacterial diversity (order) was higher in skin and mucus than in water. Order composition was more similar between the two shark species. Alpha-diversities (Shannon and Simpson) for OTUs (clusters of sequences defined by a $97 \%$ identity threshold for the16S rRNA gene) were high and there were non-significant differences between elasmobranch species or types of samples. We found orders of potentially pathogenic bacteria in water samples collected from the area where the animals were found, such as Pasteurellales (i.e. genus Pasteurella spp. and Haemophilus spp.) and Oceanospirillales (i.e. genus Halomonas spp.) but these were not found in the skin or mucus samples from any species. Some bacterial orders, such as Flavobacteriales, Vibrionales (i.e. genus Pseudoalteromonas), Lactobacillales and Bacillales were found only in mucus and skin samples. However, in a co-occurrence analyses, no significant relationship was found among these orders (strength less than $0.6, p$-value $>0.01$ ) but significant relationships were found among the order Trembayales, Fusobacteriales, and some previously described marine environmental Bacteria and Archaea, including Elusimicrobiales, Thermoproteales, Deinococcales and Desulfarculales. This is the first 
study focusing on elasmobranch microbial communities. The functional role and the benefits of these bacteria still needs understanding as well as the potential changes to microbial communities as a result of changing environmental conditions. 
Description of the microbiota in epidermal mucus and skin of sharks (Ginglymostoma cirratum and Negaprion brevirostris) and one stingray (Hypanus americanus)

Susana Caballero ${ }^{1 *}$, Ana María Galeano Mora ${ }^{*}$, Juan Diego Lozano ${ }^{1}$, Martha Josefina Vives ${ }^{2}$

${ }^{1}$ Laboratorio de Ecología Molecular de Vertebrados Acuáticos, LEMVA, Biological Sciences Department, Universidad de los Andes, Carrera 1 No. 18A-10, Bogota, Colombia

2 Centro de Investigaciones Microbiológicas, CIMIC, Biological Sciences Department, Universidad de los Andes, Carrera 1 No. 18A-10, Bogotá, Colombia

Corresponding Author:

Susana Caballero ${ }^{1}$

Email address: sj.caballero26@uniandes.edu.co

*These authors share first authorship of this manuscript

1 16S rRNA datasets used in this manuscript with accompanying metadata has been submitted to

2 Dryad as https://datadryad.org/stash/dataset/doi:10.5061/dryad.b5mkkwh8j

3 Data was also uploaded to Figshare: https://figshare.com/s/64b4fedaae 5cc0423b0d 


\begin{abstract}
Skin mucus in fish is the first barrier between the organism and the environment but the role of skin mucus in protecting fish against pathogens is not well understood. During copulation in sharks, the male bites the female generating wounds, which are then highly likely to become infected by opportunistic bacteria from the water or from the male shark's mouth. Describing the microbial component of epithelial mucus may allow future understanding of this first line of defense in sharks. In this study, we analyzed mucus and skin samples obtained from 19 individuals of two shark species and a stingray: the nurse shark (Ginglymostoma cirratum), the lemon shark (Negaprion brevirostris) and the southern stingray (Hypanus americanus). Total DNA was extracted from all samples, and the bacterial 16S rRNA gene (region V3-V4) was amplified and sequenced on the Ion Torrent Platform. Bacterial diversity (order) was higher in skin and mucus than in water. Order composition was more similar between the two shark species. Alphadiversities (Shannon and Simpson) for OTUs (clusters of sequences defined by a 97\% identity threshold for the16S rRNA gene) were high and there were non-significant differences between elasmobranch species or types of samples. We found orders of potentially pathogenic bacteria in water samples collected from the area where the animals were found, such as Pasteurellales (i.e. genus Pasteurella spp. and Haemophilus spp.) and Oceanospirillales (i.e. genus Halomonas spp.) but these were not found in the skin or mucus samples from any species. Some bacterial orders, such as Flavobacteriales, Vibrionales (i.e. genus Pseudoalteromonas), Lactobacillales and Bacillales were found only in mucus and skin samples. However, in a co-occurrence analyses, no significant relationship was found among these orders (strength less than $0.6, p$-value $>0.01$ ) but significant relationships were found among the order Trembayales, Fusobacteriales, and some previously described marine environmental Bacteria and Archaea, including Elusimicrobiales, Thermoproteales, Deinococcales and Desulfarculales. This is the first study focusing on elasmobranch microbial communities. The functional role and the benefits of these bacteria still needs understanding as well as the potential changes to microbial communities as a result of changing environmental conditions.
\end{abstract}

Keywords: microbiota, Negaprion brevirostris, Ginglymostoma cirratum, Hypanus americanus, skin, mucus, Ion Torrent 
Introduction

The first barrier of protection against microorganisms in fish is the mucosal immune system (Cone, 2009). This system protects fish physically, chemically, and biologically from threats or pathogens found in their habitat (Subramanian, MacKinnon \& Ross, 2007; Subramanian, Ross \& Mackinnon, 2008; Raj et al., 2011). The mucosal immune system is subdivided into three subgroups that correspond to the locations where the mucus is secreted: the gut, the gills and the skin (Salinas, Zhang \& Sunyer, 2011). Some studies suggest that this mucus is constantly renewed, reducing the pathogenic load found on the surface of the fish (Nagashima et al., 2003). The mucus is secreted in higher quantities as a response to threat (Mittal \& Datta Munshi, 1974; Gostin, Neagu \& Vulpe, 2011; Rai et al., 2012), and this viscous substance consists of molecules that may help in healing and protecting the skin (Cameron \& Endean, 1973; Al-Hassan et al., 1985), including the secretion of antimicrobial and regenerative compounds (Hansen \& Olafsen, 1999).

The epithelial mucus is sometimes considered an ideal surface for bacterial adhesion. In fact, the accumulation of microorganisms appears to take place during the lifetime of the individual (Hansen \& Olafsen, 1999), leading to the establishment of the microbiota in fish skin. However, it is also recognized that the mucus has a concentration of molecules that prevent the adhesion of pathogenic bacteria (Crouse-Eisnor, Cone \& Odense, 1985). As such, the role or the relationship between the mucus and environmental bacteria is not clear (Luer, 2012). It has been suggested that bacteria found in this layer may play three possible roles (Salminen et al., 2010): a) bacteria may stimulate mucus and antimicrobial compound production, b) bacteria may activate and help modulate the immune response in the fish, and c) the interaction between different types of bacteria may actively exclude or compete with potentially pathogenic bacteria.

The mucus layer in sharks and rays has been poorly studied. However, it is known that mucus from stingray skin appear to accelerate the healing processes of wounds, and that bacteria found in the mucus present antibacterial activity against human pathogens (Luer et al., 2014). Also, it has been found recently that the structure, geometry and arrangement of dermal denticles of the shark skin play an important role in allowing bacterial attachment and development of biofilms (Chien et al., 2020). Reproductive behavior in this group is characterized by aggressiveness during courtship and copulation (Pratt \& Carrier, 2001; Carrier, Pratt \& Martin, 2015). In sharks, the male bites the female on her dorsal or pectoral fins generating wounds in those areas (Pratt \& Carrier, 2001). Polyandry, a mating system in which one female mates with multiple males, is very common in some species (Saville et al., 2002; Carrier et al., 2003). This behavior drives competition between males and avoidance in females (Klimley, 1980; Gordon, 1993; Pratt \& Carrier, 2001). There are also morphological characteristics related to this trait. Sexual dimorphism occurs in shark species in which the male's teeth are shaped so they can easily grab the female in order to remain close to her while mating. Females have thicker dermal denticles (tooth-like structures that provide hydrodynamics and protection) than males as protection against these bites (Carrier, Musick \& Heithaus, 2012). In the case of rays, the females prick the male with their caudal spine (Pratt \& Carrier, 2001). It has been shown in some stingray species that when many males are involved in mating, a few may die in the process (Gilad et al., 2008). In spite of these apparently aggressive behaviors, copulation is necessary and the wounds provoked are highly likely to become infected (Daly-Engel et al., 2010) due to opportunistic bacteria in the water and in the oral cavity of males. Because of the high concentration of pathogenic microorganisms found in the aquatic environment 
81 (Magnadottir, 2010), it is important to determine the microbiota component of the epithelial 82 mucus, the skin, and to understand whether the bacteria found in these are similar or different from 83 those found in the water surrounding the animals. This will help to understand the role of mucus 84 in the protection against pathogens. In this study, we characterized the bacterial diversity in the 85 epithelial mucus in three elasmobranch species, the nurse shark (Ginglymostoma cirratum), the 86 lemon shark (Negaprion brevirostris) and the southern stingray (Hypanus americanus) (Last et al., 87 2016). We also hypothesize about the possible role of some of the bacteria found in the mucus and 88 in the skin.

89

Materials and Methods

\section{Sample collection}

Mucus and skin tissue samples were collected from 19 apparently healthy individuals (no visible wounds, normal swimming activity); 14 of them from animals captured in Bimini, Bahamas $\left(25^{\circ} 43^{\prime} 59 \mathrm{~N}, 79^{\circ} 14^{\prime} 60 \mathrm{~W}\right)$ : four corresponded to juvenile nurse sharks (Ginglymostoma cirratum), six to juvenile lemon sharks (Negaprion brevirostris), and four to adult southern stingrays (Hypanus americanus). Samples from an additional five adult nurse sharks were collected at Oceanario from Islas del Rosario (CEINER), in the Colombian Caribbean $\left(10^{\circ} 10^{\prime} 30 \mathrm{~N}, 75^{\circ} 45^{\prime} 00\right.$ W). For each individual, we obtained a sample of skin tissue and mucus, following sampling protocols approved by the Animal Care Committee of Universidad de los Andes (CICUAL) (Bogota, Colombia). The skin tissue sample was cut, using a sterile blade for each specimen, from the posterior part of the dorsal fin $\left(1 \mathrm{~cm}^{3}\right.$ or less) and the mucus from the skin surface, using a sterile $1.5 \mathrm{ml}$ microcentrifuge tube to scrape the skin surface, ideally filling at least half of the tube. Animals were manipulated for approximately 5 minutes and immediately released. A water sample was also collected in sterile $15 \mathrm{ml}$ tube from the sampling location of each individual. Thus, three samples were associated with each individual, for a total of 57 samples. The individuals were captured and raised slightly above the surface of the water, so that the samples could be taken outside the water, while the animal could continue breathing. Skin samples were preserved in ethanol $90 \%$. All samples were maintained at $4{ }^{\circ} \mathrm{C}$ for less than one week, until processing.

\section{DNA Extraction and PCR amplification}

DNA was extracted from the entire sample collected for all samples. The Tissue and Cells DNA Isolation Kit (MoBio Laboratories, Inc.) was used, following the manufacturer instructions. Water samples were filtered through a $0.8 \mu \mathrm{m}$ cellulose nitrate filter before DNA extraction. The primers $515 \mathrm{f}$ and $806 \mathrm{r}$ were used in order to amplify the region $\mathrm{V} 4$ from the bacterial and archaea 16S rRNA gene using the primers 515F ( $5^{\prime}$-GTGCCAGCMGCCGCGGTAA-3') and 806R (5'GGACTAHVGGGTWTCTAAT-3') (Caporaso et al., 2010). PCR amplification conditions were as follows: an initial denaturation at $94{ }^{\circ} \mathrm{C}$ for 3 minutes, followed by 35 cycles of denaturing at $94{ }^{\circ} \mathrm{C}$ for 45 seconds, annealing for 45 seconds at $50{ }^{\circ} \mathrm{C}$ and extension for 45 seconds at $72{ }^{\circ} \mathrm{C}$, followed by a final extension of 20 minutes at $72{ }^{\circ} \mathrm{C}$. A negative PCR control was always included to reduce the chance of contaminant amplification. Successful amplification was confirmed on $1 \%$ agarose gel.

Ion torrent library preparation, quantification and sequencing From the 57 samples, 32 were used to construct libraries (Supplementary Table 1). Samples were 
127 chosen depending on their final DNA concentration, once the PCR products were cleaned using 128 magnetic beads and run on a 1.5\% agarose gel. Only the samples that had a clear strong band 129 were used for library construction. Two libraries, each with 16 barcodes, were prepared using the 130 protocol Ion Xpress ${ }^{\mathrm{TM}}$ Plus gDNA Fragment Library Preparation (Life Technologies). Libraries 131 were quantified with the Qubit kit. Templates were prepared following the Ion PGM ${ }^{\mathrm{TM}}$ Template 132 OT2 200 Kit (Life Technologies) protocols. Libraries were prepared for sequencing using the 133 protocol Ion PGM ${ }^{\mathrm{TM}}$ Sequencing 200 Kit v2 (Life Technologies). Libraries were pooled to

134 equimolar concentration and loaded on two Ion 316 chips and sequenced in the Ion Torrent PGM 135 (Life Technologies).

136

16S rRNA datasets used in this manuscript with accompanying metadata has been submitted to Dryad as https://datadryad.org/stash/dataset/doi:10.5061/dryad.b5mkkwh8j

\section{Bioinformatic and statistical analyses}

Sequences were separated by barcodes directly by the Ion Torrent PGM and saved by the ion reporter in different files; sequence quality was analyzed using FastQC (Andrews, 2014). The file format was changed from Fastq to Fasta. Demultiplexing was conducted by comparing the mapping file of the chip with the files containing the sequences. For the core diversity analysis, Qiime2 (Bolyen et al. 2019) was used via command line using the moving pictures tutorial as reference. The files were imported as "MultiplexedSingleEndBarcodeInSequence" and demultiplexed using "cutadapt", eliminating sequences shorter than $50 \mathrm{bp}$. The sequences went through DADA2 (Callahan et al. 2016) for quality control to delete sequences with lower qscore than 20 and then the remaining sequences were aligned de novo with align-to-tree-mafftfastree. In parallel, the sequences were clustered into OTUs used to perform non phylogenetic analysis. The rooted tree obtained with fasttree2 (Price et al. 2010) was used to perform an alpha rarefaction with a 1000 sequence depth. For taxonomic assignment, analyses were performed on the Galaxy online platform (Afgan et al. 2016) following one amplicon data workflow on Mothur v.1.28.0 (Schloss et al., 2009). This workflow started by merging all read files into group files. Group files were identified as samples from each of the three elasmobranch species and also as type of sample (skin, mucus or water). The next step of the workflow identified unique sequences and generated a file with these sequences and a second file in which the number of each unique representative sequence was kept. Following this, reads were filtered based on quality and length. Parameters to remove low quality sequences (quality control) was for those with less than 20 Phred score and shorter than $50 \mathrm{bp}$. (minimum length) followed by a step to remove poorly aligned sequences and chimeric sequences. Finally, reads were clustered based on their degree of similarity, with a minimum of $97 \%$ identity threshold and aligned to the Silva V4 reference database (Quast et al., 2013), followed by a classification step into taxonomic categories (order, family, genus and species when possible).

Rstudio version 1.1.463 (R Development Core Team, 2010) was used (Wickham, 2009) for alpha ( $\alpha$ ) diversity analyses (Simpson and Shannon) (package Vegan) (Oksanen et al. 2015) which were conducted for OTUs, using the number of OTUs per sample, comparing among species $(N$. brevirostris, G. cirratum juveniles and adults and $H$. americanus) and among sample types (tissue, mucus and water). In this analysis, OTUs with less than $0.2 \%$ presence were not included. A Shapiro-Wilk normality test was conducted to evaluate normality among samples belonging to 
173 each elasmobranch species (Supplementary Table 1), including the additional category of adults 174 and juvenile for nurse sharks, or to each category of sample type before performing any statistical 175 tests. Since results fell outside the normality assumption, a Kruskal-Wallis test was used to 176 evaluate whether $\alpha$ diversity was significantly different among elasmobranch species or among 177 sample type. To estimate beta ( $\beta$ ) diversity (Bray-Curtis dissimilarity index and a Principal 178 Component Analysis (PCA) the taxonomic category "order" was used. Venn diagrams (package 179 DVenn) were used to visualize shared orders among elasmobranch species and among sample 180 types.

In order to find co-occurrence between different bacterial and/or Archaea orders a correlation matrix was created in R using the Spearman's co-efficient as in Ju et al (2013). Correlations had to be stronger than 0.6 with a p-value $<0.01$ to be considered to have a significant co-occurrence with other orders. All orders, including those with less than $0.2 \%$ presence were included in the co-occurrence analysis. A chord plot was created to visualize the relations between the different orders.

\section{Results}

The 32 samples used to build the libraries included a mucus or tissue sample for each of the individuals sampled and only four of the 19 samples from water (Supplementary Table 1). The other samples, including 15 water samples, had low DNA concentrations that could not be used for NGS sequencing analysis, characterized by weak or no bands amplified. A total of 219,162 reads were obtained from the Ion Torrent PGM of which 55,642 were used for subsequent analyses following demultiplexing. After read quality control and chimera removal, 21,530 reads were used in the following steps for Qiime2 and in the Mothur workflow. Of these, 17,685 were grouped as unique OTUs in Qiime2 (most of them represented each by only one read, Supplementary Figure 1) ( $82 \%$ total reads). In Mothur, 3,639 (16.9\% total reads) were assigned taxonomically against the SilvaV4 database while 19,164 were left unassigned ( $84 \%$ total reads); sequences assigned taxonomically belonged to 18 mucus, 10 skin and 4 water samples.

A total of 25 phyla, 81 orders, 76 families and 33 genera were assigned (Figure 1), but analyses were restricted to OTUs and to the taxonomic category "order", since this was the category with higher levels of taxonomic assignments. Most reads were identified as belonging to the Bacteria Domain (Supplementary Table 2). Occurrence of reads belonging to the kingdom Archaea was low $(<2 \%)$ and these were only found in one mucus sample from one nurse shark. Among the Archaea Domain, the orders identified were Micrarchaeles, Cenarchaeales, Halobacteriales, and Methanobacteriales. Thirty-seven orders were shared between samples from the three elasmobranch species and the water samples, and 17 were solely found in elasmobranch samples. Twenty-seven orders were found only in the water samples (Figure 1). Fifty-four were shared among all elasmobranch species, 28 were shared between the nurse shark and the lemon shark, and 25 were shared between the two shark species and the southern stingray (Figure 2a). Fortyfive orders were shared between all sample types (water, mucus and skin), 47 were shared between mucus and skin, and less than 20 were shared between tissue or mucus and water samples (Figure 2b). Also, among elasmobranch species and types of samples, similar orders were found in every sample and with a similar distribution (Figure $3 a$ and $3 b$ ). The highest abundance was of the order 
219 Actinomycetales and the family Nocardiaceae (i.e.genus Rhodococcus), with a slightly greater 220 abundance of reads obtained from the lemon shark and less abundance for reads obtained from the 221 southern stingray. Mucus and skin samples had a higher number of reads than water samples 222 (Supplementary Figure 2).

223

224

225

226

227

228

229

230

231

232

233

234

235

236

237

238

239

240

241

242

243

244

245

246

247

248

249

250

251

252

253

254

255

256

257

258

259

260

261

262

263

264

Phylogenetic diversity was used to build a rarefaction curve, following a phylogenetic aligned tree method, as it allowed a better visualization of data since most rarefaction curves were too similar to be distinguished. However, this methodology allowed clearer observation of the high heterogeneity found in samples used in this study, with some samples having much a higher number of total reads than others. Also, it showed that most if not all the samples did not reach an asymptote as showed in Supplementary Figure 3. For OTUs, Alpha-diversity was similar among species and among types of samples (Table $1 \mathrm{a}$ and $1 \mathrm{~b}$ ). Alpha-diversity was non significantly different among species or among type of samples (Figure $4 a, 4 b, 4 c$ and $4 d$ ).

Using the taxonomic category "order", the Bray-Curtis dissimilarity index, used as a $\beta$ diversity estimate, revealed greater dissimilarity $(0.45)$ between the microbial communities found in the tissue and mucus of the southern stingray and those found in the shark species, the lemon shark, and nurse shark, and less dissimilarity (0.30) between the communities found in the skin and mucus of the lemon shark and nurse shark (Figure 5). When each sample was used to calculate the BrayCurtis dissimilarity index, patterns of bacterial community dissimilarity were less clear, but it appears that mucus and skin samples from sharks and the southern stingray were less dissimilar from each other than when compared with the water samples (Figure 6).

The percentage for each order identified from the total reads (sequences) obtained for each sample and analyzed is shown in Supplementary Table 2 and Supplementary Figure 2. Few sequences were assigned to the species or genus levels. Most of them were assigned to higher taxonomic levels (order). However, among the genus and species identified, several reported bacterial fish pathogens, symbionts and commensals were found in the mucus, tissue, and water samples (Supplementary Table 2 and Supplementary Table 4). It is interesting to note that some fish pathogens were only found in the water and not in the mucus/tissue samples, such as the order Pastereullales (i. e. Pasteurella spp., Haemophilus spp) and Oceanospirillales (i.e. Halomonas spp.)

The PCA showed higher similarity between the bacterial orders found in the skin and mucus of the two shark species in comparison with those in the southern stingray. Similarities were due to a similar number and distribution of reads identified as belonging to the order Actinomycetales (dimension 1) and to reads belonging to the order Bacteroidales (dimension 2) (Figure 7). In the PCA separating each sample, including adults and juvenile nurse sharks, no clear differentiation patterns among microbial community compositions were detected (Supplementary Figure 4).

The co-occurrence analysis plot showed 104 out of all 202 recognized orders (including orders with less than $0.2 \%$ presence) (Supplementary Figure 5). Most of the correlations were between candidate orders, however orders such as Chlorobiales, Deinococcales Trembayales, Thermoproteales, Desulfarculales and Fusobacteriales showed strong co-occurrence. Orders such as Actinomycetales and Bacteroidales, highly influential in the principal coordinate analysis, where not found in the co-occurrence analyses plot. 


\section{Discussion}

270

271

272

273

274

275

276

277

278

279

280

281

282

283

284

285

286

287

288

289

290

291

292

293

294

295

296

297

298

299

300

301

302

303

304

305

306

307

308

309

310

This study provides initial but useful baseline information on microbial communities in elasmobranch species from which changes in microbial communities over time and under changing conditions can be evaluated. Nevertheless, depending on the characteristics and populations of these animals, the composition and role of the whole community may vary. From a conservation perspective, knowledge of the microbial composition and function may be an important approach for understanding how these organisms may be affected in the long term by environmental change; for example, climate change or ocean acidification (Bahrndorff et al., 2016).

In general, there were few taxonomically identified sequences compared to the total (only $16.9 \%$ of the total reads) and as compared to OTUs grouped ( $82 \%$ of the total reads). This may be the result of the shorter length of the sequences, the kits used in sequencing (to make libraries of short sequences), and differences in the DNA concentration at the start of the amplification and library preparation processes (Solonenko et al., 2013). Also, it has been suggested that the primers used in this study may amplify DNA from the host species (eukaryotic DNA), which would then reduce the total number of microbial reads that would have been included in our analysis (Parada et al., 2016). However, our results are relevant to understand the microbial communities in elasmobranch fish and they suggest that skin tissue and mucus communities of the three elasmobranch species were similar in composition. Also, although some orders were shared with the water samples, more of them were shared between the two shark species and to a lesser extent with the southern stingray. Alpha-diversity at OTU level was similar among samples from the three species and among types of samples. However, there was high variation in the Alphadiversity among samples within each species or within each sample type, which was confirmed by the rarefaction curve ran for all samples included in the study. This could be related with different number of reads obtained per sample, since alpha diversity indices can be sensitive to differences in sample sizes (Barrantes \& Sandoval, 2009). This could have been caused by the storage conditions of some samples or due to the loss of DNA from some samples during the different steps of library preparation. Also, selective PCR amplification could generate higher amplification of some bacteria and not others. The richness of species was higher in mucus samples and in lemon shark samples. Composition of mucus samples and skin samples from sharks tended to be more similar to each other than to the southern stingray or the water samples.

In this study, the bacterial diversity in the mucus and tissue included a wide range of orders, that have been described as pathogens, non-pathogens, and some that have scarcely been studied in relation to potential or confirmed hosts. Most orders identified belonged to the Bacteria Domain, with a very small proportion of Archaea. However, some of the Archaea identified in a mucus sample belonging to a nurse shark included Cenarchaeales, which have been found to be symbionts of one marine sponge that lives at very low temperatures (Preston et al., 1996). Interestingly, a high proportion of Actinomycetales (i.e. genus Rhodococcus) were found in mucus and tissue samples and influenced the community composition of all our samples, as showed in the PCA. 
311 Although Actinomycetales can be found in environmental samples from soil and water, and have 312 been found in marine water and sediments, some strains have been isolated from marine 313 environments and produce antimicrobial compounds against pathogenic bacterial and fungus 314 (Betancur et al., 2017), particularly against some pathogenic strains of E. coli and Pseudomonas 315 sp. (Yellamanda et al., 2016). The phylum Actinobacteria, to which the order Actinomycetales 316 belongs, has also been found in the skin microbiota of bony fish (Osteichthyes) (Larsen et al., 317 2013). The finding of some Actinomycetales also in the water samples may represent 318 contamination, although as mentioned before, they are an abundant order in marine environments. 319 Also, a negative control was always included in the PCR amplifications and came out clean in all 320 cases. Also, by not including OTUs or orders with less than $0.2 \%$ representation in the total sample, we tried to control for possible contaminants in the samples, maybe due to manipulation in the field or in the laboratory setting.

Although we focused our analysis on microbial community diversity and composition of the orders identified, we also investigated their characteristics and those of the genera within each order because, although a smaller number of reads were identified to the genus level, some interesting data was obtained. Within the bacterial order and genera found only in water samples, three have been described as pathogens for fish, including the order Pasteurellales (genus Pasteurella spp. and Haemophilus spp.) and of the order Oceanospirillales (genus Halomonas spp.) (Bullock, 1961; Hawke et al., 1987; Austin, 2005). There was also a species only found in water samples, Acinetobacter johnsonii (order Pseudomonadales), which has been described as a fish pathogen (Kozińska et al., 2014). Other sequenced bacteria present in the results of water samples, such as Moraxella sp., are opportunistic bacteria and have been found in other animals, for example in mammals (Whitman, 2015). Some orders found only in the elasmobranch samples may also play a role as pathogens. The order Alteromonadales (i.e. genera Alteromonas, Shewanella) (Boone \& Bryant, 1980), Actinomycetales (i.e. genera Mycobacterium and Nocardia), Bacillales (i.e. Staphylococcus) and Flavobacteriales (i.e. Chryseobacterium) have been reported as pathogens for various fish species (Hansen \& Olafsen, 1999; Austin, 2005). The order Syntrophobacterales (i.e. genus Syntrophobacter) was also present in mucus and skin samples and considered a possible pathogen for fish, due to the fact that bacteria that belong to this group, degrade propionate, a corticoid used in healing skin (Schulze et al., 2006). However, many other Flavobacteriales (i.e. Flavobacterium), Vibrionales (i.e. Pseudoalteromonas), Lactobacillales (i.e. Lactobacillus) and Bacillales (i.e. Bacillus), also found only in elasmobranch samples, are considered symbionts of marine fish (Anand et al., 2011; Luer et al., 2014). Some species of Flavobacterium have been studied as commensal to fish, and have shown antimicrobial activity against fish pathogens from the genus Vibrio (Lal \& Tabacchioni, 2009). Bacillus polymyxa, found in mucus and skin samples in this study, has been isolated from fish guts and some strains of this species synthesize antibiotics (Olmos, 2014). Similarly, Bacillus subtilis has been suggested as a probiotic involved in the optimization of fish feeding (Merrifield \& Rodiles, 2015). Finally, various orders sequenced from mucus and skin samples are considered normal biota of fish gills or skin (i.e., Xanthomonadales, Caulobacteriales) (Sugita et al., 1996).

However, it is important to remember that pathogenicity may be related to particular strains (Fitzgerald \& Musser, 2001) so caution is needed in the interpretation of these results. For example, three orders genera found in mucus and tissue samples Lactobacillales (i.e. Streptococcus and Enterococcus), Pseudomonadales (i.e. Pseudomonas) and Vibrionales (i.e. Vibrio) are sometimes

Peer) reviewing PDF | (2018:07:29887:5:1:NEW 22 Sep 2020) 
357 reported as pathogens and sometimes reported as symbionts. For example, S. parauberis produces 358 streptococcosis in some fish (Austin, 2005; Nho et al., 2009; Abrahamian \& Goldstein, 2011), but 359 other Streptococcus spp. inhibit the growth of pathogenic bacteria (Hansen \& Olafsen, 1999). 360 Similarly, Pseudomonas putrefaciens acts as a pathogen for fish (Abrahamian \& Goldstein, 2011), 361 but P. fluorescens inhibits growth of pathogens (Subramanian, Ross \& MacKinnon, 2008) and has 362 been isolated from healthy salmon eggs and mucus (Cipriano \& Dove, 2011; Akinyemi et al., 363 2016). Finally, Vibrio have been reported several times as an important pathogen for marine life 364 because of its great capacity for survival and of acclimation in its host, as it hydrolyzes urea and uses it as a source of carbon and nitrogen (Hansen \& Olafsen, 1999). Many species have been described as infectious for Negaprion brevirostris, especially when they are physically injured (Grimes et al., 1984a; Grimes, Gruber \& May, 1985); others are associated to the mortality of sharks in captivity (Grimes et al., 1984b), and others to infections caused by hooks (Borucinska et al., 2002). There are some species that, depending on the strain, are pathogenic or not, such as $V$. alginolyticus and V. parahemoliticus (Austin \& Austin, 2007; Abrahamian \& Goldstein, 2011). Other species, such as Vibrio alginolyticus and $V$. fluviales, are considered pathogenic for fish in general (Zorrilla et al., 2003); Vibrio fortis has been reported as a sea horse pathogen (Wang et al., 2016); Vibrio shilonii has been found to cause coral bleaching (Kushmaro et al., 2001).

There are various bacteria identified in the mucus samples that are considered in other studies as symbionts or pathogens for other animals or humans. For example, some species of the order Bacteroidales (i.e. Bacteroides) have been described as human pathogens in periodontal disease and Prevotella copri, found in mucus and skin samples have been identified as pathogens in intestinal inflammation. Additionally, bacteria from the order Clostridiales (i.e. Helcoccocus) have also been described as pathogens for humans (Chow \& Clarridge, 2014). Also, many species within the order Chlamydiales are reported as pathogens for birds and mammals (Whitman, 2015).

382

383

384

As examples of symbiosis of species of bacteria (found in samples for this study) with humans or other animals, it is worth mentioning Lactobacillus zeae (order Lactobacillales), which has been found to serve as protective biota for nematodes (Zhou et al., 2014); Butyrivibrio and Selenomonas (both from the order Clostridiales) are found in the gastrointestinal tract of ruminants; other members of the order Clostridiales, including Faecalibacterium prausnitzii, Peptoniphilus, Ruminococcus, Megamonas (Chow \& Clarridge, 2014) and Butyricimonas (from the order Bacteroidales) (Wexler, 2007) are normal important bacteria in the human gut microbiota. Other orders sequenced from mucus samples were Flavobacteriales such as Sulcia muelleri (Moran, Tran \& Gerardo, 2005), Enterobacteriales such as Baumannia cicadellinicola (Cottret et al., 2010) and

392 Trembayales such as Carsonella ruddii (Thao et al., 2000), which have been described in symbiotic association with insects. A very interesting case is the order Burkholderiales (i.e. Janthinobacterium lividum), which has been found in the skin of some amphibians and appears to prevent infection by Batrachochytrium dendrobatidis (Brucker et al., 2008). These are startling examples that may be related to the findings of this study; however, more in-depth research should be conducted to identify the pathogenicity or symbiosis properties specifically in elasmobranch or fish.

Results from the co-occurrence analysis presented some interesting results but not clear patterns related to the PCA results or to other previously presented analyses. Strong co-occurences were 402 found among orders such as Elusimicrobiales, Halanaerobiales, Synachococcales, Solibacterales 
403 which are defined as marine environmental bacteria (some of these orders can be classified as 404 cyanobacteria), including some desulfurating bacteria, such as Desulfarculales, but also with 405 bacterial order characterized by their presence in extreme habitats, such as Thermobaculales and 406 Thermoproteales. This could suggest that either these are random co-occurrences among 407 environmental bacteria that may be contaminants to the mucus and skin samples or that 408 desulfuration may be an important metabolic path used by bacteria in these microbial communities 409 as has been shown in the gut microbial communities of some marine fish (Egerton et al., 2018). 410 Further research on this idea may be warranted. Interestingly, Fusobacteriales, a bacterial order 411 which has been previously found in the human gut (Suau et al., 2001) as well as in the gills of coral 412 reef fish (Reverter et al., 2017), as well as Trembayales, an order of bacteria found to be 413 endosymbionts of insects (Thao et al., 2000), were also found in the co-occurrence analyses, 414 suggesting a possible role in the skin and mucus microbial communities of elasmobranch.

415

416 According to this study, the role of the mucus and the bacteria associated to it may depend on 417 numerous variables, including the virulence and pathogenicity of each microorganism (Hansen \& 418 Olafsen, 1999). Opportunistic bacteria can acquire virulence determinants with environmental 419 changes by different means, for example, by a) increasing their numbers by exploiting the higher

438 The simultaneous presence of pathogens and possible symbionts varied between samples;
439 however, the role of each order should be verified for each of the host species considered in this production of mucus (glycoproteins) induced by presence of toxic substances in the water (Hansen \& Olafsen, 1999), by b) shifting from a non-infectious state to an infectious one through an activation caused by a physical or chemical change in the environment (Hansen \& Olafsen, 1999), or by c) Reaching the dermal layer to infect the host taking advantage of a degree of reduction of the defensive mucus layer, caused by the presence of abrasive substances in the surroundings of the fish (Benhamed et al., 2014). These three opportunities for the bacteria to infect the hosts not only benefit these microorganisms but they also affect the host by reducing their physiological condition (Austin, 2005), and may explain the finding of the reported bacterial pathogens on the skin of healthy animals.

The orders considered fish pathogens found in the water samples but absent in the elasmobranch samples, allows this research to present an interesting assumption. We suggest that there may be specific antimicrobial activity in the skin environment, or partial control against infections that exists in low concentration in the mucus, but this might be also a result of the low number of samples and replicates analyzed (Rakers et al., 2010). However, it is very likely that difficulties in sampling -for example, handling the sharks and stingrays-, prevented us from collecting a larger skin or mucus sample and that this in itself could be biasing our results. analysis. According to these results, we suggest that the role of the epithelial microbiota may be considered as a first line of defense against infectious organisms but it could also be a potential threat for the injured host. This may be particularly relevant as a protective mechanism for sharks and rays that get hurt during copulation and that could otherwise die due to infected wounds. This could also depend on the whole combination of bacteria and their interaction between them in each host, as well as with the host cell and physiology, known as the "holobiont" (Carthey et al., 2020). As mentioned earlier, each fish may accumulate a specific community of microorganisms in its life span depending on the environments it inhabits during its development and growth (Hansen \& Olafsen, 1999). This particular accumulation and interaction between the microbiota and the host 
449

450

451

452

453

454

455

456

457

458

459

460

461

462

463

464

465

466

467

468

469

470

471

472

473

474

475

476

477

478

479

480

481

482

483

484

485

486

487

488

489

490

491

492

493

494

(holobiont) may also affect aspects such as survival and reproduction of the host, and may become relevant for conservation of these shark species in the near future (Carthey et al., 2020).

This study represents the first contribution to describing shark and ray skin and mucus microbial communities. The next steps to further understand the role of bacterial communities in skin and mucus of elasmobranchs require functional metagenomics and metabolomics analyses to unveil the role of these bacteria.

\section{Conclusions}

This study presents the first description of skin and mucus microbiota from two shark species and a stingray. Orders were highly diverse and similar between species and types of samples and a higher number of orders were found in skin and mucus when compared to water samples. The order Actinomycetales was found in a very high percentage $(>50 \%)$ of skin and mucus samples and could represent bacteria that may have antimicrobial activity, however the co-occurrence analysis showed strong relationships among order previously found in the human and fish gut, as endosymbionts of insects and among orders involved in metabolic paths related to desulfuration. This is baseline information that could help in future monitoring of microbiota change in elasmobranch species that may be caused by climate change and ocean acidification.

\section{Conflict of interest}

We declare potential conflict of interest with Dr. M. Suzuki. For that reason, we ask for him not to be asked as a reviewer or editor for this manuscript.

\section{Author contribution}

Susana Caballero: project and experiment design, manuscript writing and data analysis

Ana Maria Galeano: project and experiment development and data analysis

Juan Diego Lozano: Data analysis

Martha Vives: Project and experiment design, manuscript writing

Funding

Financial support for this project was provided by Proyecto de Ciencias Básicas, Vicerrectoria de Investigaciones, Universidad de los Andes.

\section{Acknowledgements}

We would like to give a special thanks to all those involved in samples collection, particularly to the Bimini Shark Laboratory, to D. Cardeñosa, and to R. Vieira and his team at Oceanario Islas del Rosario (Ceiner). We thank E. Salguero and A. P. Jimenez for their help with sequencing. 
References

500

501

502

503

504

505

506

507

508

509

510

511

512

513

514

515

516

517

518

519

520

521

522

523

524

525

526

527

528

529

530

531

532

533

534

535

536

537

538

539

540

Abrahamian FM., Goldstein EJC. 2011. Microbiology of animal bite wound infections. Clinical microbiology reviews 24:231-46. DOI: 10.1128/CMR.00041-10.

Afgan E., Baker D., van den Beek M., Blankenberg D., Bouvier D., Čech M., Chilton J., Clements D., Coraor N., Eberhard C., Grüning B., Guerler A., Hillman-Jackson J., Von Kuster G., Rasche E., Soranzo N., Turaga N., Taylor J., Nekrutenko A., Goecks J. 2016. The Galaxy platform for accessible, reproducible and collaborative biomedical analyses:2016 update. Nucleic Acids Research 44(W1): W3-W10 doi:10.1093/nar/gkw343

Akinyemi AA., Ekelemu JK., Oyelakin OO., Oloyede AR., Green BM. 2016. Molecular characterization of bacteria associated with the African catfish Clarias gariepinus (Burchell, 1822) from Yew-Mata station on Yewa river by 16s gene sequencing method. Global Journal of Bio-Science and Biotechnology 5:295-300.

Al-Hassan JM., Thomson M., Criddle KR., Summers B., Criddle RS.. 1985. Catfish epidermal secretions in response to threat or injury. Marine Biology 88:117-123.

Anand P., Chellaram TC., Kumaran S., Shanthini F. 2011. Screening for antibiotic producing marine bacteria against fish pathogens. International Journal of Pharma and Bio Sciences 2:B314-B325.

Andrews S. 2014. FastQC: A Quality Control Tool for High Throughput Sequence Data. Available online at: http://www.bioinformatics.babraham.ac.uk/projects/fastqc/ (Accessed Dec 11, 2014).

Austin B. 2005. Bacterial Pathogens of Marine Fish. In: Belkin S., Colwell R.R. (eds) Oceans and Health: Pathogens in the Marine Environment. Springer, Boston, MA. pp: 391-413.

Austin B., Austin DA. 2007. Bacterial Fish Pathogens: diseases of farmed and wild fish. Springer.

Bahrndorff S., Alemu T., Alemneh T., Nielsen JL. 2016. The microbiome of animals: implications for conservation biology. International Journal of Genomics ID 5304028. DOI: $10.1155 / 2016 / 304028$.

Barrantes G., Sandoval L. 2009. Conceptual and statistical problems associated with the use of diversity indices in ecology. International Journal of Tropical Biology 57: 451-460.

Benhamed S., Guardiola FA., Mars M., Esteban MÁ. 2014. Pathogen bacteria adhesion to skin mucus of fishes. Veterinary microbiology 171:1-12. DOI: 10.1016/j.vetmic.2014.03.008.

Betancur L., Naranjo-Gaybor SJ., Vinchira-Villaraga DM., Moreno-Sarmiento NC., Maldonado LA., Suarez-Moreno ZR., Acosta-González A., Padilla-González GF., Puyana M, Castellanos L., Ramos FA. 2017. Marine Actinobacteria as a source of compounds for phytopatogen control: an integrative metabolic-profilling/ bioactivity and taxonomical approach. Plos One 12(2): e0170148.

Bolyen E., Rideout JR., Dillon MR, et al (92 other authors). 2019. Reproducible, interactive, scalable and extensible microbiome data science using QIIME 2. Nature Biotechnology 37: $852-857$.

Boone DR., Bryant MP. 1980. Propionate-Degrading Bacterium, Syntrophobacter wolinii sp. nov. gen. nov., from Methanogenic Ecosystems. Applied and Environmental Microbiology 
541

542

543

544

545

546

547

548

549

550

551

552

553

554

555

556

557

558

559

560

561

562

563

564

565

566

567

568

569

570

571

572

573

574

575

576

577

578

579

580

581

582

583

584

585

586

40:626-632.

Borucinska J., Kohler N., Natanson L., Skomal G. 2002. Pathology associated with retained fishing hooks in blue sharks, Prionace glauca, with implications for their conservation. Journal of Fish Diseases 25:515-521. DOI: 10.1046/j.1365-2761.2002.00396.x.

Brucker RM., Harris RN., Schwantes CR., Gallaher TN., Flaherty DC., Lam BA., Minbiole KPC. 2008. Amphibian Chemical Defense: Antifungal Metabolites of the Microsymbiont Janthinobacterium lividum on the Salamander plethodon cinereus. Journal of Chemical Ecology 34:1422-1429. DOI: 10.1007/s10886-008-9555-7.

Bullock GL. 1961. A schematic outline for the presumptive identification of bacterial diseases of fish. The Progressive Fish-Culturist 23:147-151. DOI: 10.1577/15488659(1961)23[147:ASOFTP]2.0.CO;2.

Callahan BJ., McMurdie PJ., Rosen MJ., Han AW., Johnson AJA., Holmes SP. 2016

DADA2: high-resolution sample inference from Illumina amplicon data. Nature Methods 13:581-583.

Caporaso JG., Kuczynski J., Stombaugh J., Bittinger K., Bushman FD., Costello EK., Fierer N., González Peña A., Goodrich K., Gordon JI., Huttley GA., Kelley ST., Knights D., Koenig JE., Ley RE., Lozupone CA., McDonald D., Muegge BD., Pirrung M., Reeder J., Sevinsky JR., Turnbaugh PJ., Walters WA., Widmann J., Yatsunenko T., Zaneveld J., Knight R.. 2010. QIIME allows analysis of high-throughput community sequencing data. Nature Methods 7:335-336.

Cameron AM., Endean R. 1973. Epidermal secretions and the evolution of venom glands in fishes. Toxicon 11:401IN1407-406IN2410.

Carrier JC., Murru FL., Walsh MT., Pratt HL. 2003. Assessing reproductive potential and gestation in nurse sharks (Ginglymostoma cirratum) using ultrasonography and endoscopy: An example of bridging the gap between field research and captive studies. Zoo Biology 22:179-187. DOI: 10.1002/zoo.10088.

Carrier JC., Musick JA., Heithaus MR. 2012. Biology of sharks and their relatives. CRC press.

Carrier JC., Pratt HL., Martin LK. 2015. Group Reproductive Behaviors in Free-Living Nurse Sharks, Ginglymostoma cirratum. Jeffrey C. Carrier, Harold L. Pratt, Jr. and Linda K (eds.) Martin Source: 1994:646-656.

Carthey AJR., Blumstein DT., Gallagher RV., Tetu SH., Gillings MR. 2020. Conserving the holobiont. Functional Ecology 34: 764-776.

Chien HW., Chen XY., Tsai WP., Lee M. 2020. Inhibition of biofilm formation by rough sharkskin-patterned surfaces. Colloids and Surfaces B:Biointerfaces 186:110738.

Chow S-K., Clarridge JE. 2014. Identification and clinical significance of Helcococcus species, with Description of Helcococcus seattlensis sp. nov. from a Patient with Urosepsis. Journal of Clinical Microbiology 52:854-858. DOI: 10.1128/JCM.03076-13.

Cipriano RC., Dove A. 2011. Far from superficial: microbial diversity associated with the dermal mucus of fish. Health and diseases of aquatic organisms: bilateral perspectives. MSU Press, East Lansing.

Cone RA. 2009. Barrier properties of mucus. Advanced drug delivery reviews 61:75-85. DOI: 10.1016/j.addr.2008.09.008.

Cottret L., Milreu PV., Acuña V., Marchetti-Spaccamela A., Stougie L., Charles H., Sagot MF.. 2010. Graph-based analysis of the metabolic exchanges between two co-resident intracellular symbionts, Baumannia cicadellinicola and Sulcia muelleri, with their insect host, Homalodisca coagulata. PLoS Computational Biology 6. 
587 Crouse-Eisnor RA., Cone DK., Odense PH. 1985. Studies on relations of bacteria with skin 588 surface of Carassius auratus and Poecilia reticulata. Journal of fish biology 27:395-402. 
633

634

635

636

637

638

639

640

641

642

643

644

645

646

647

648

649

650

651

652

653

654

655

656

657

658

659

660

661

662

663

664

665

666

667

668

669

670

671

672

673

674

675

676

677

Lal S., Tabacchioni S. 2009. Ecology and biotechnological potential of Paenibacillus polymyxa: a minireview. Indian Journal of Microbiology 49:2-10. DOI: 10.1007/s12088-009-0008-y. Larsen A., Tao Z., Bullard SA., Arias C R. 2013. Diversity of the sin microbiota of fishes: evidence for host species specificity. FEMS Microbiology Ecology 85: 483-494.

Last PR., Naylor GJ., Manjaji-Matsumoto, BM. 2016. A revised classification of the family Dasyatidae (Chondrichthyes: Myliobatiformes) based on new morphological and molecular insights. Zootaxa 4139: 345-368.

Luer C. 2012. Novel Compounds from Shark and Stingrays Epidermal Mucus with Antimicrobial Activity Against Wound Infection Pathogens. Report. Award W81XWH, Mote Marine Laboratory, Sarasota, Florida, USA.

Luer C., Walsh C., Ritchie K., Edsberg L., Wyffels J., Luna V., Bodine A. 2014. Novel compounds from shark and stingray epidermal mucus with antimicrobial activity against wound infection pathogens. Mote Marine Lab, Sarasota FL. In press:1-39.

Magnadottir B. 2010. Immunological control of fish diseases. Marine biotechnology 12:361379.

Merrifield D., Rodiles A. 2015. The fish microbiome and its interactions with mucosal tissues. In: Mucosal Health in Aquaculture. 273-289.

Mittal AK., Datta Munshi JS. 1974. On the regeneration and repair of superficial wounds in the skin of Rita vita (Ham.)(Bagridae, Pisces). Cells Tissues Organs 88:424-442.

Moran NA., Tran P., Gerardo NM. 2005. Symbiosis and insect diversification: an ancient symbiont of sap-feeding insects from the bacterial phylum Bacteroidetes. Applied and environmental microbiology 71:8802-10. DOI: 10.1128/AEM.71.12.8802-8810.2005.

Nagashima Y., Kikuchi N., Shimakura K., Shiomi K. 2003. Purification and characterization of an antibacterial protein in the skin secretion of rockfish Sebastes schlegeli. Comparative Biochemistry and Physiology Part C: Toxicology \& Pharmacology 136:63-71. DOI: 10.1016/S1532-0456(03)00174-1.

Nho S-W., Shin G-W., Park S-B., Jang H-B., Cha I-S., Ha M-A., Kim Y-R., Park Y-K., Dalvi RS., Kang B-J., Joh S-J., Jung T-S. 2009. Phenotypic characteristics of Streptococcus iniae and Streptococcus parauberis isolated from olive flounder (Paralichthys olivaceus). FEMS Microbiology Letters 293:20-27. DOI: 10.1111/j.1574-6968.2009.01491.x.

Oksanen J., Blanchet F., Kindt R., Legendre P., Minchin P., O'Hara R., Simpson GL., Solymos P., Stevens MHH., Wagner H. 2015. Vegan: Community Ecology Package . R package version 2.3-1. Available online at: http://CRAN.R-project.org/package=vegan.

Olmos J. 2014. Bacillus subtilis: A potential probiotic bacterium to formulate functional feeds for aquaculture. Journal of Microbial \& Biochemical Technology 6:361-365. DOI: 10.4172/1948-5948.1000169.

Parada AE., Needham DM., Fuhrman JA. 2016. Every base matters: assesing small subunit rRNA primers for marine microbiomes with mock communities, time series and global field samples. Environmental Microbiology 18: 1403-1414.

Pratt HL., Carrier JC. 2001. A review of elasmobranch reproductive behavior with a case study on the nurse shark, Ginglymostoma cirratum. Environmental Biology of Fishes 60:157-188. DOI: 10.1023/A:1007656126281.

Preston CM., Wu KY., Molinski TF., DeLong EF. 1996. A psychrophilic crenarchaeon inhabits a marine sponge: Cenarchaeum symbiosum gen. nov., sp. nov. Proceedings of the National Academy of Sciences of the USA 93: 6241-6246.

Peer) reviewing PDF | (2018:07:29887:5:1:NEW 22 Sep 2020) 
678 Price MN., Dehal PS., Arkin AP. FastTree 2-approximately maximum-likelihood trees for large

679

680

681

682

683

684

685

686

687

688

689

690

691

692

693

694

695

696

697

698

699

700

701

702

703

704

705

706

707

708

709

710

711

712

713

714

715

716

717

718

719

720

721

722

723 alignments. PLoS ONE. 2010;5:e9490

Quast C., Pruesse E,. Yilmaz P., Gerken J., Schweer T., Yarza P., Peplies J., Glöckner FO. 2013. The SILVA ribosomal RNA gene database project: improved data processing and web-based tools. Nucleic Acids Research 41: 590-596.

R Development Core Team. 2010. R: A Language for Statistical Computing . Vienna: R Foundation for Statistical Computing.

Rai AK., Srivastava N., Nigam AK., Kumari U., Mittal S., Mittal AK. 2012. Healing of cutaneous wounds in a freshwater teleost, Labeo rohita: scanning electron microscopical investigation. Microscopy research and technique 75:890-897.

Raj VS., Fournier G., Rakus K., Ronsmans M., Ouyang P., Michel B., Delforges C., Costes B., Farnir F., Leroy B., Wattiez R., Melard C., Mast J., Lieffrig F., Vanderplasschen A. 2011. Skin mucus of Cyprinus carpio inhibits cyprinid herpesvirus 3 binding to epidermal cells. Veterinary Research 42:1-10. DOI: 10.1186/1297-9716-42-92.

Rakers S., Gebret M., Uppalapati S., Meyer W.. Maderson P., Sell AF., Kruse C, Paus R. 2010. "Fish matters": the relevance of fish skin biology to investigative dermatology. Experimental Dermatology 19:313-324. DOI: 10.1111/j.1600- 0625.2009.01059.x.

Reverter M., Sasal P., Tapissier-Bontemps N., Lecchini D., Suzuki M. 2017. Characterisation of the gill mucosal bacterial communities of four butterflyfish species:a reservoir of bacterial diversity in coral reef ecosystems. FEMS Microbiology Ecology 93: fix051. doi: 10.1093/femsec/fix051.

Salinas I., Zhang Y-A., Sunyer JO. 2011. Mucosal immunoglobulins and B cells of teleost fish. Developmental and comparative immunology 35:1346-65. DOI: 10.1016/j.dci.2011.11.009.

Salminen S., Nybom S., Meriluoto J., Collado MC., Vesterlund S., El-Nezami H. 2010. Interaction of probiotics and pathogens - benefits to human health? Current Opinion in Biotechnology 21:157-167.

Saville KJ., Lindley AM., Maries EG., Carrier JC., Pratt HL. 2002. Multiple paternity in the nurse shark, Ginglymostoma Cirratum. Environmental Biology of Fishes 63:347-351. DOI: 10.1023/A:1014369011709.

Schloss PD., Westcott SL., Ryabin T., Hall JR., Hartmann M., Hollister EB., Lesniewski RA., Oakley BB., Parks DH., Robinson CJ., Sahl JW., Stres B., Thallinger GG., Van Horn DJ., Weber CF. 2009. Introducing Mothur: Open-Source, Platform-Independent, Community-Supported Software for Describing and Comparing Microbial Communities. Applied and Environmental Microbiology, 75 (23), pp. 7537-7541

Schulze AD., Alabi AO., Tattersall-Sheldrake AR., Miller KM. 2006. Bacterial diversity in a marine hatchery: Balance between pathogenic and potentially probiotic bacterial strains. Aquaculture 256:50-73. DOI: 10.1016/j.aquaculture.2006.02.008.

Solonenko SA., Ignacio-Espinoza JC.. Alberti A., Cruaud C., Hallam S., Konstantinidis K., Tyson G., Wincker P., Sullivan MB. 2013. Sequencing platform and library preparation choices impact viral metagenomes. BMC Genomics 14:320. DOI: https://doi.org/10.1186/1471-2164-14-320

Suau A., Rochet V., Sghir A., Gramet G., Brewaeys S., Sutren M., Rigottier-Gois L,. Doré J. 2001. Fusobacterium prausnitzii and related species represent a dominant group within the human fecal flora. Systematics and Applied Microbiology 24: 139-145.

Subramanian S., MacKinnon SL., Ross NW. 2007. A comparative study on innate immune parameters in the epidermal mucus of various fish species. Comparative biochemistry and 
724

725

726

727

728

729

730

731

732

733

734

735

736

737

738

739

740

741

742

743

744

745

746

747

748

749

750

751

752

753

754

755

756

757

758

759

760

761

762

763

764

765

766

767

768

769

physiology. Part B, Biochemistry \& molecular biology 148:256-63. DOI: 10.1016/j.cbpb.2007.06.003.

Subramanian S., Ross NW., Mackinnon SL. 2008. Comparison of the biochemical composition of normal epidermal mucus and extruded slime of hagfish (Myxine glutinosa). Fish \& shellfish immunology 25:625-32. DOI: 10.1016/j.fsi.2008.08.012.

Subramanian S., Ross NW., MacKinnon SL. 2008. Comparison of antimicrobial activity in the epidermal mucus extracts of fish. Comparative biochemistry and physiology. Part B, Biochemistry \& molecular biology 150:85-92. DOI: 10.1016/j.cbpb.2008.01.011.

Sugita H., Shibuya K., Shimooka H., Deguchi Y. 1996. Antibacterial abilities of intestinal bacteria in freshwater cultured fish. Aquaculture 145:195-203. DOI: 10.1016/S00448486(96)01319-1.

Thao ML., Moran NA., Abbot P., Brennan EB., Burckhardt DH., Baumann P. 2000. Cospeciation of psyllids and their primary prokaryotic endosymbionts. Applied and Environmental Microbiology 66:2898-2905. DOI: 10.1128/AEM.66.7.2898-2905.2000.

Wang X., Zhang Y., Qin G., Luo W.. Lin Q. 2016. A novel pathogenic bacteria (Vibrio fortis) causing enteritis in cultured seahorses, Hippocampus erectus Perry, 1810. Journal of fish diseases 39:765-9. DOI: 10.1111/jfd.12411.

Wexler HM. 2007. Bacteroides: the good, the bad, and the nitty-gritty. Clinical Microbiology 20:593-621.

Whitman WB. 2015. Bergey's manual of systematics of Archaea and Bacteria. New York: Wiley.

Wickham H. 2009. ggplot2: Elegant Graphics for Data Analysis. NewYork,NY: Springer.

Yellamanda B., Vijayalakshmi M., Kavitha A.. Reddy DK., Venkateswarlu. 2016. Extraction and bioactive profile of the compounds produced by Rhodococcus sp VLD-10. 3 Biotech 6:261. DOI: 10.1007/s13205-016-0576-6.

Zhou M., Yu H., Yin X., Sabour PM., Chen W., Gong J. 2014. Lactobacillus zeae protects Caenorhabditis elegans from enterotoxigenic Escherichia coli-caused death by inhibiting enterotoxin gene expression of the pathogen. PLoS ONE 9.

Zorrilla I., Morinigo MA., Castro D., Balebona MC., Borrego JJ. 2003. Intraspecific characterization of Vibrio alginolyticus isolates recovered from cultured fish in Spain. Journal of Applied Microbiology 95:1106-1116. DOI: 10.1046/j.1365-2672.2003.02078.x.

Peer] reviewing PDF | (2018:07:29887:5:1:NEW 22 Sep 2020) 
770

771

772

773

774

775

776

777

778

779

780

781

782

783

784

785

786

787

788

789

790

791

792

793

794

795

796

797

798

799

800

801

802

803

804

805

806

807

808

809

810

811

812

813

814

815
Figure legends

Figure 1. Summary of taxonomic assignments. Venn diagram showing the number of orders shared among elasmobranch samples (mucus and tissue), and water samples. Also, orders unique to either elasmobranch samples (brown circle) or water samples (blue circle).

Figure 2. Orders (a) shared between and among elasmobranch species and those unique to each species. Orders (b) shared between and among sample types and those unique to each sample type.

Figure 3. Bacterial order (a) composition found for each elasmobranch species (Hypanus americana, Ginglymostoma cirratum and Negaprion brevirostris). Bacterial order (b) composition found for each sample type.

Figure 4. Box-plots showing Alpha-diversity was non significantly different among species for OTUs (a)Shannon and (b) Simpson or among sample type for OTUs (c) Shannon and (d) Simpson.

Figure 5. Bray-Curtis dissimilarity index tree showing greater dissimilarity $(0.45)$ between the microbial communities (at order level) found in the tissue and mucus of the southern stingray and those found in the shark species, the lemon shark, and nurse shark, and less dissimilarity (0.30) between the communities found in the tissue and mucus of the lemon shark and nurse shark.

Figure 6. Bray-Curtis dissimilarity index calculated at order level for different types of sample for different elasmobranch species showing mucus and tissue samples from sharks and the southern stingray being less dissimilar from each other than when compared with the water samples.

Figure 7. Principal component analysis (PCA) showed higher similarity between the bacterial communities found in the tissue and mucus of the two shark species in comparison with those in the southern stingray at both order and family levels. Similarities were due to a similar number and distribution of reads identified as belonging to the order Actinomycetales and to the family Nocardiaceae (dimension 1) and to reads belonging to the order Bacteroidales (dimension 2).

Supplementary Figure 1. Bacterial order composition found in each sample successfully amplified in this study.

Supplementary Figure 2. Number of OTUs grouped and their frequency.

Supplementary Figure 3. Faith's phylogenetic diversity index. Growth rate of the Faiths pd in place of standard rarefaction curve, showing fast increase of diversity with sequencing depth per sample (N\#). 
816

817 Supplementary Figure 4. Principal component analysis (PCA) showed no clear pattern of similarity 818 among all samples included in this study. No clear pattern of similarity was observed among 819 juvenile nurse shark or adult nurse shark samples.

820

821 Supplementary Figure 5. Chord diagram showing co-occurrence of bacterial orders among all 822 samples. 


\section{Figure 1}

Summary of taxonomic assignments.

Venn diagram showing the number of orders shared among elasmobranch samples (mucus and tissue), and water samples. Also, orders unique to either elasmobranch samples (brown circle) or water samples (blue circle). 


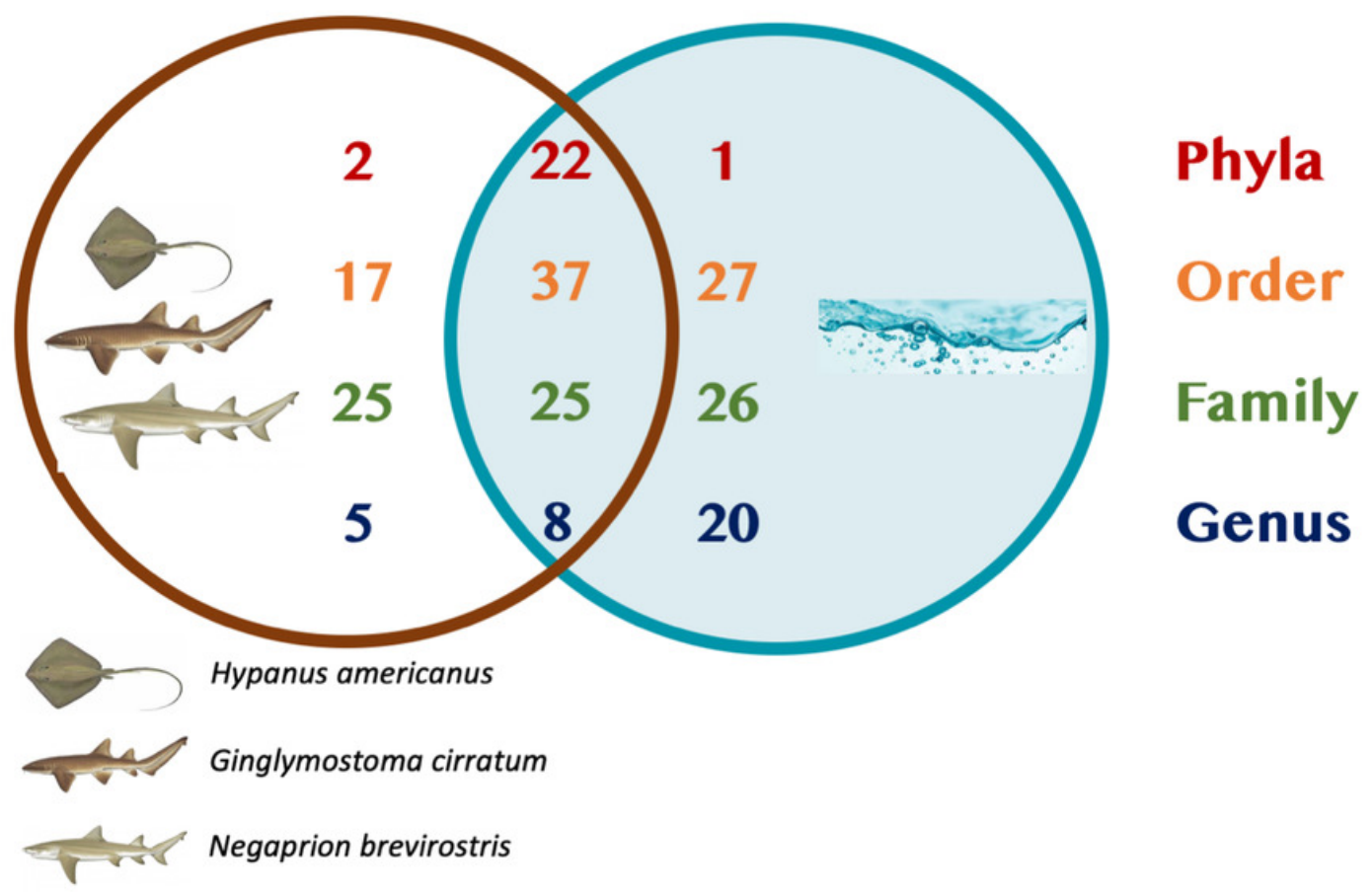


Figure 2

Figure 2. Orders shared

Orders (a) shared between and among elasmobranch species and those unique to each species. Orders (b) shared between and among sample types and those unique to each sample type 
a. Species- Order

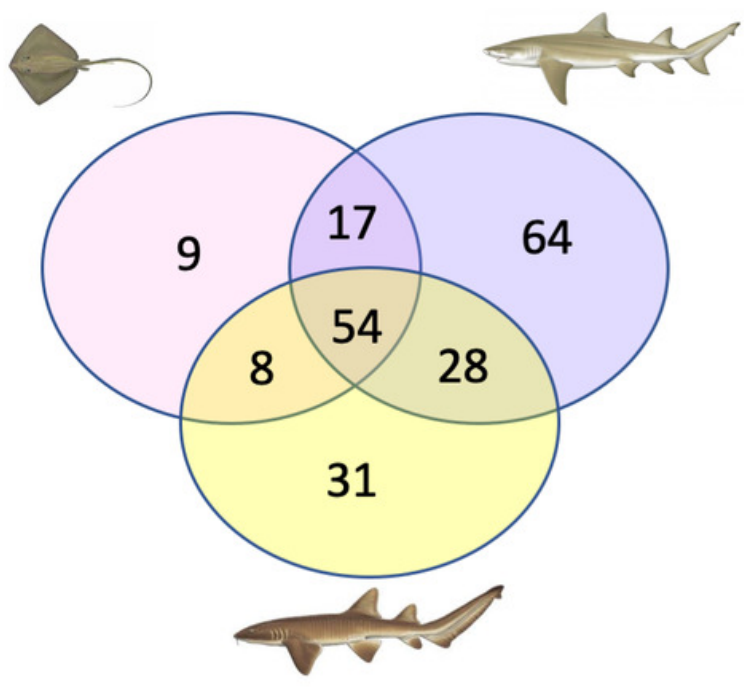

Negaprion brevirostris Ginglymostoma cirratum Hypanus americanus

b. Type of Sample- Order

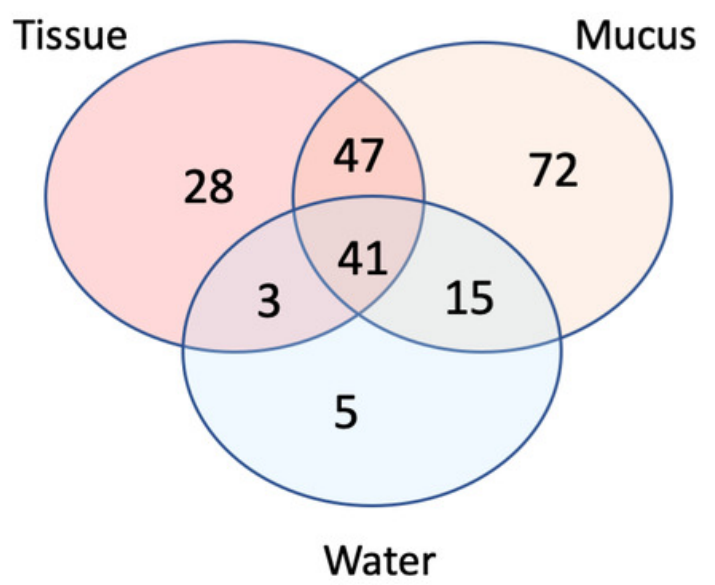




\section{Figure 3}

Figure 3. Bacterial Order Composition

Bacterial order (a) composition found for each elasmobranch species (Hypanus americana, Ginglymostoma cirratum and Negaprion brevirostris). Bacterial order (b) composition found for each sample type. 

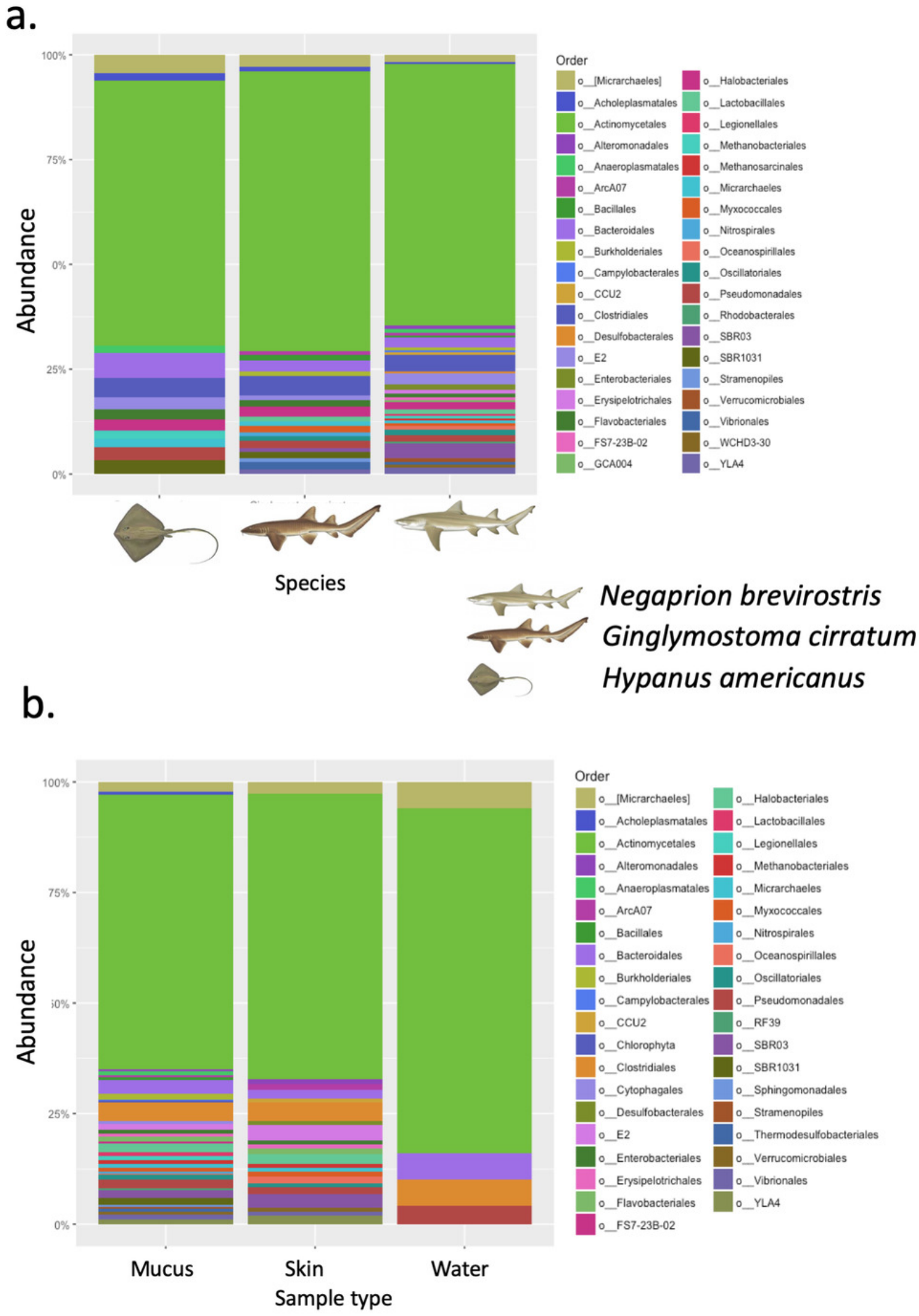
Figure 4

Figure 4. Alpha diversity of OTUs

Figure 4. Box-plots showing Alpha-diversity was non significantly different among species for OTUs (a)Shannon and (b) Simpson or among sample type for OTUs (c) Shannon and (d) Simpson. 
a.

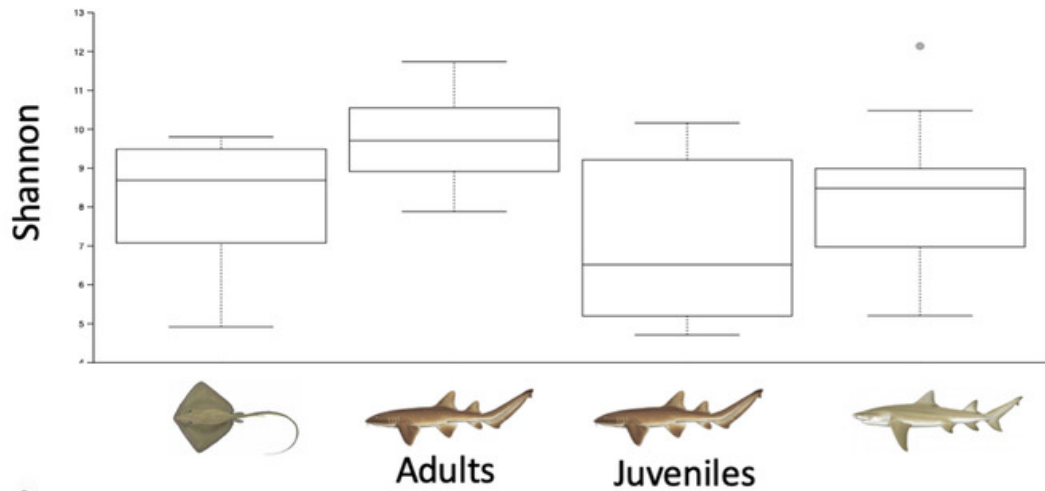

b.

Juveniles
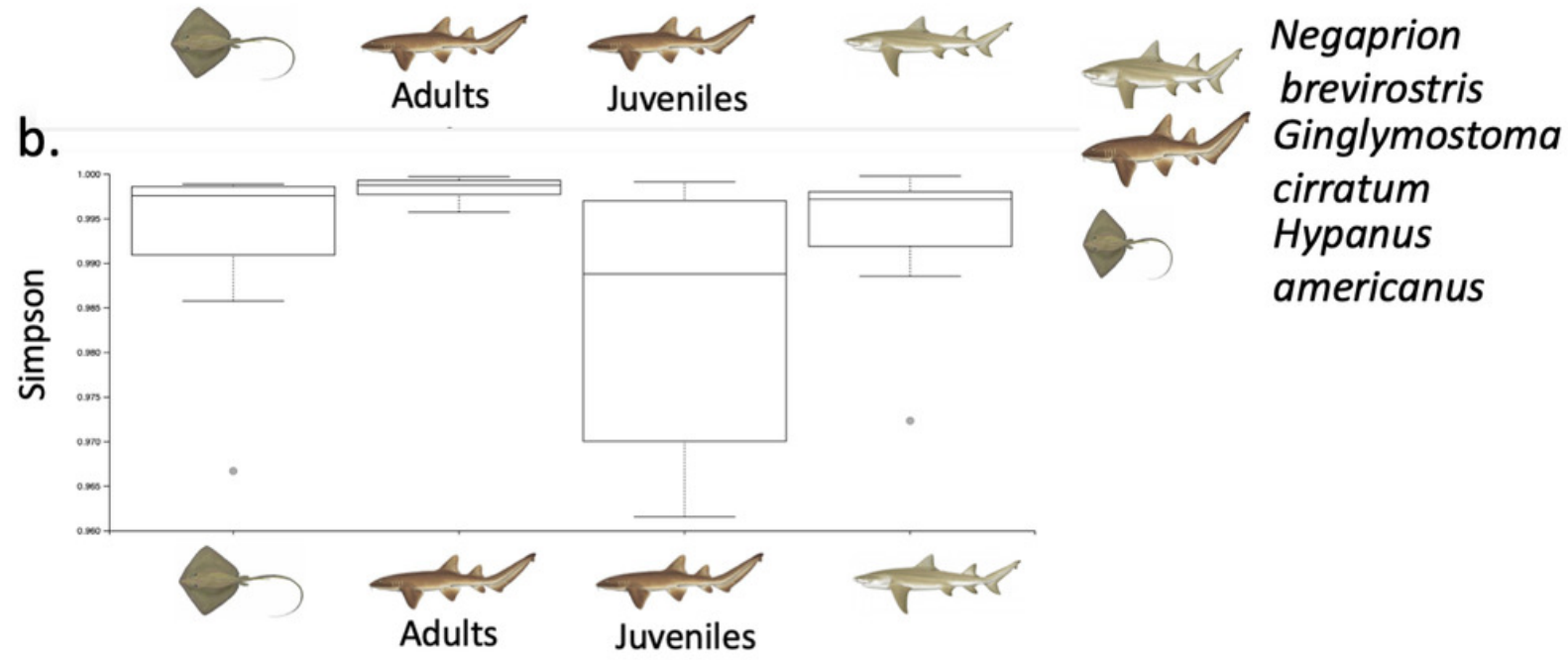

c.
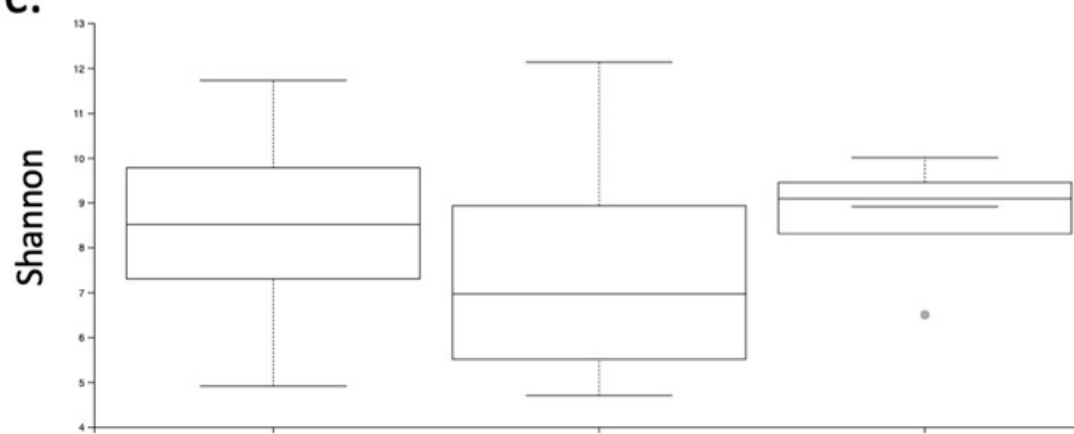

Mucus

Tissue

Water

d.

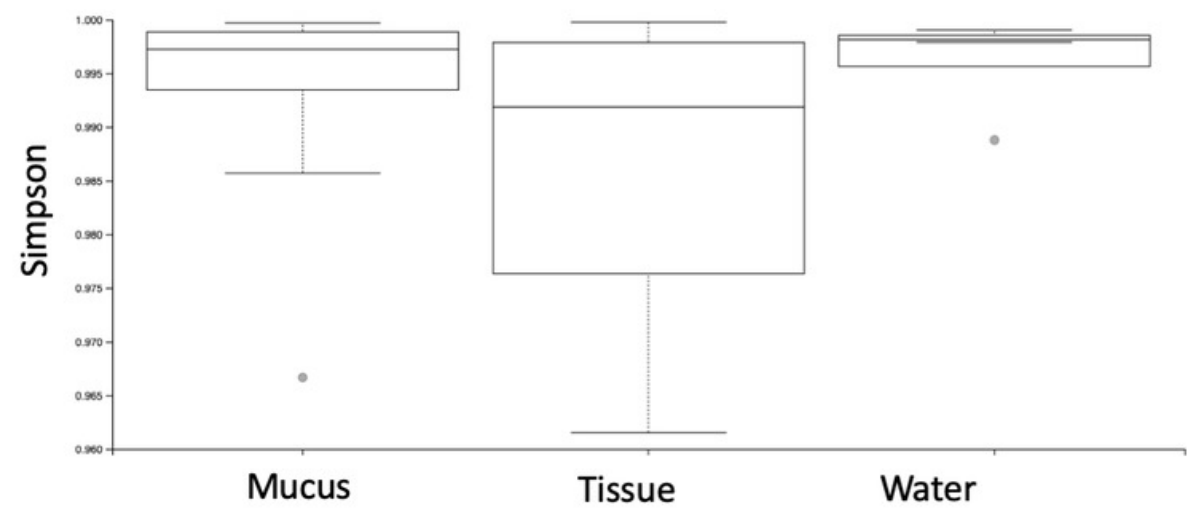




\section{Figure 5}

Bray-Curtis dissimilarity index tree orders

Figure 5. Bray-Curtis dissimilarity index tree showing greater dissimilarity $(0.45)$ between the microbiome communities (for order) found in the tissue and mucus of the southern stingray and those found in the shark species, the lemon shark, and nurse shark, and less dissimilarity (0.30) between the communities found in the tissue and mucus of the lemon shark and nurse shark. 


\section{Order}

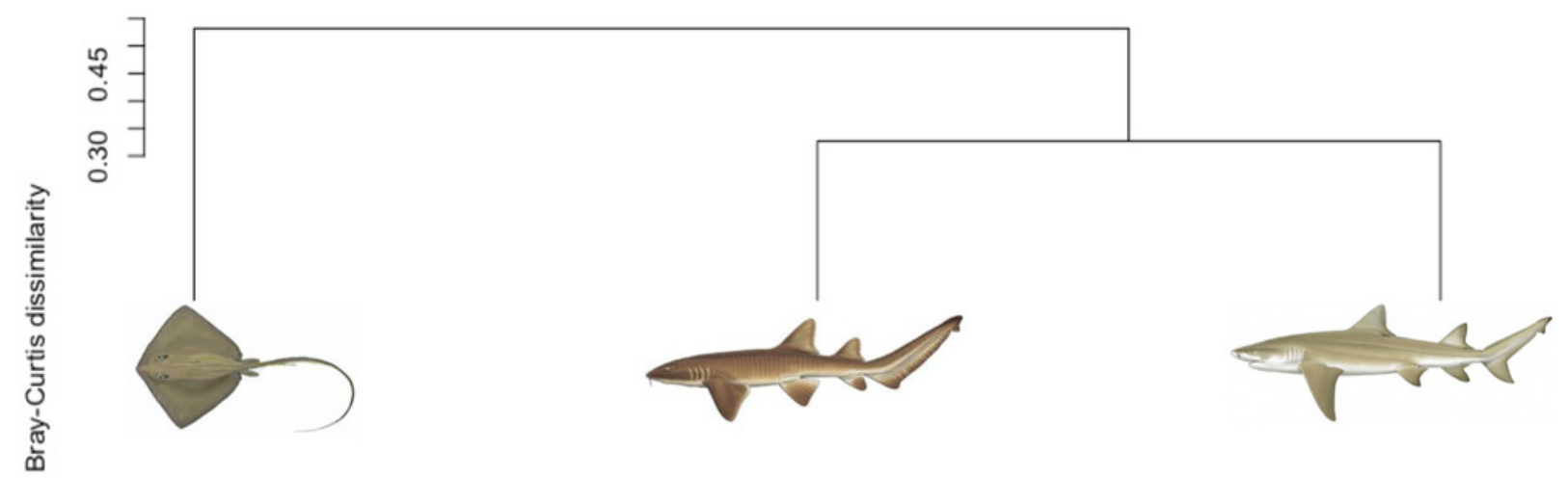

Negaprion brevirostris
Ginglymostoma cirratum
Hypanus americanus 
Figure 6

Bray-Curtis dissimilarity index calculated for order for different types of sample

Figure 6. Bray-Curtis dissimilarity index calculated for order for different types of sample for different elasmobranch species showing mucus and tissue samples from sharks and the southern stingray being less dissimilar from each other than when compared with the water samples.

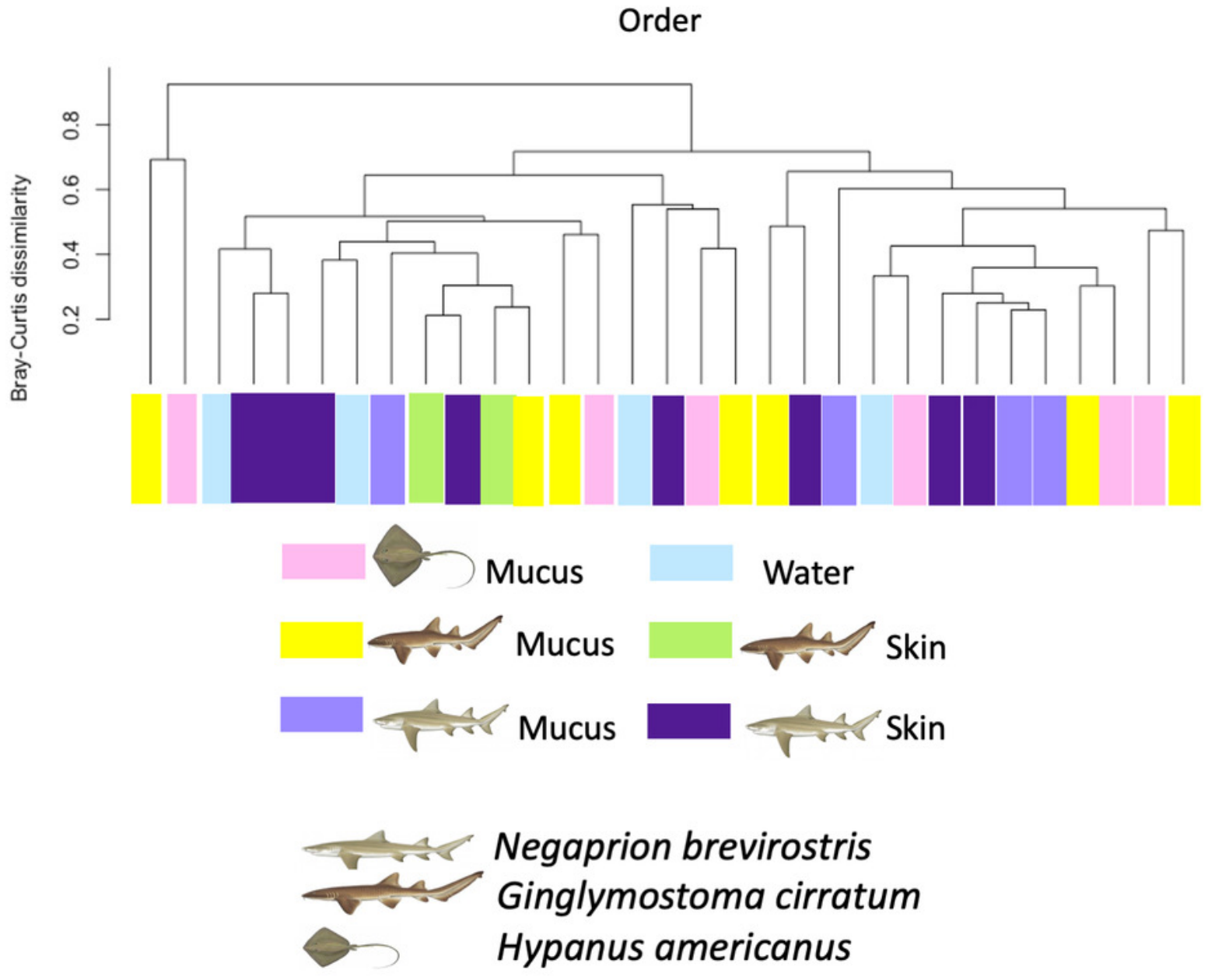




\section{Figure 7}

Principal component analysis (PCA)

Figure 7. Principal component analysis (PCA) showed higher similarity between the bacterial communities found in the tissue and mucus of the two shark species in comparison with those in the southern stingray at both order and family levels. Similarities were due to a similar number and distribution of reads identified as belonging to the order Actinomycetales and to the family Nocardiaceae (dimension 1 ) and to reads belonging to the order Bacteroidales (dimension 2). 


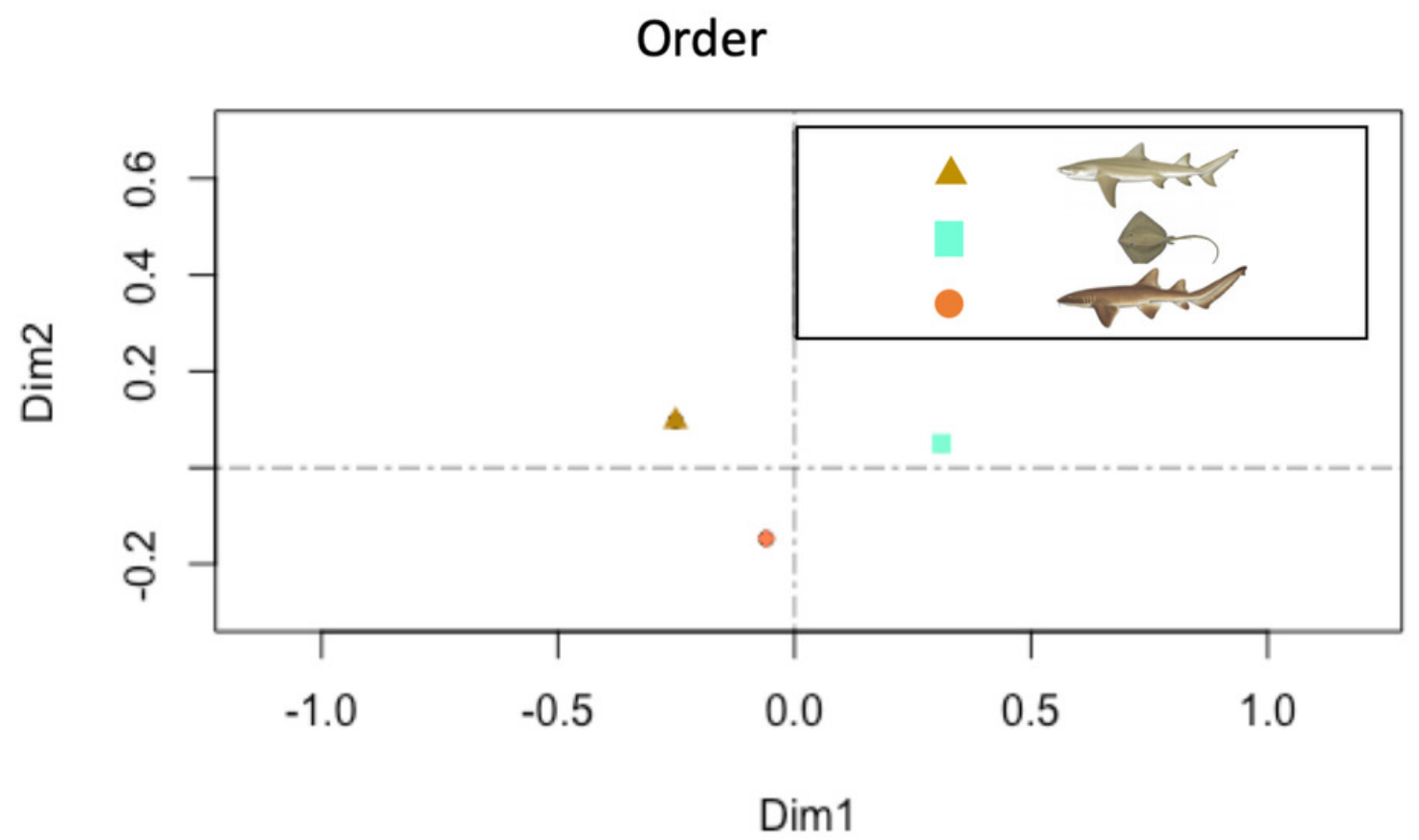




\section{Table 1 (on next page)}

\section{Alpha diversity of OTUs}

Table 1. Alpha-diversity indices for OTUs of bacteria found in this study (Shannon and

Simpson) calculated by a) elasmobranch species and b) type of sample. For Shannon and Simpson the mean and range (in parenthesis) are reported. 
1 Table 1. Alpha-diversity indices for OTUs of bacteria found in this study (Shannon and Simpson) calculated by a) elasmobranch species and b) type of sample. For Shannon and Simpson the mean and range (in parenthesis) are reported.

4 a)

\begin{tabular}{|c|c|c|}
\hline \multirow{2}{*}{ Species } & \multicolumn{2}{|c|}{ OTUs } \\
\cline { 2 - 3 } & Shannon & Simpson \\
\hline Hypanus americanus $(\mathrm{n}=7)$ & 8.06 & 0.991 \\
$(4.90-9.80)$ & $(0.966-0.998)$ \\
\hline $\begin{array}{c}\text { Ginglymostoma cirratum } \\
\text { (Juveniles, } \mathrm{n}=7)\end{array}$ & $\begin{array}{c}7.77 \\
(4.70-11.72)\end{array}$ & $\begin{array}{c}0.984 \\
0.961-0.999)\end{array}$ \\
\hline $\begin{array}{c}\text { Ginglymostoma cirratum } \\
(\text { Adults, } \mathrm{n}=3)\end{array}$ & 9.08 & 0.997 \\
Negaprion brevirostris & $(7.87-10.14)$ & $(0.995-0.999)$ \\
$(\mathrm{n}=15)$ & 8.16 & 0.993 \\
& $(5.19-12.12)$ & $(0.972-0.999)$ \\
\hline
\end{tabular}

5

b)

\begin{tabular}{|c|c|c|}
\hline \multirow{2}{*}{ Type of sample } & \multicolumn{2}{|c|}{ OTUs } \\
\cline { 2 - 3 } & Shannon & Simpson \\
\hline Tissue & 7.41 & 0.986 \\
$(\mathrm{n}=10)$ & $(4.70-12.12)$ & $(0.961-0.999)$ \\
\hline Mucus & 8.42 & 0.993 \\
$(\mathrm{n}=18)$ & $(4.90-11.72)$ & $(0.966-0.999)$ \\
\hline Water & 8.66 & 0.995 \\
$(\mathrm{n}=4)$ & $(6.49-10)$ & $(0.997-0.999)$ \\
\hline
\end{tabular}

7

8 